\title{
Enterotoxicity of clinical and environmental isolates of Aeromonas spp.
}

\author{
D. V. SINGH and S. C. SANYAL*
}

Department of Microbiology, Institute of Medical Sciences, Banaras Hindu University, Varanasi 221005, India

\begin{abstract}
Summary. Of 147 isolates of three species of Aeromonas, 54 were from clinical and 93 from environmental sources. When tested for enterotoxin production, most of the isolates $(56 \%)$ caused accumulation of fluid in rabbit ileal loops (RILs). Although large proportions of clinical and environmental isolates of $A$. caviae ( $55 \%$ and $65 \%$, respectively) elicited such a response in RILs, isolates of $A$. hydrophila and $A$. sobria produced significantly more fluid (p < 0.05). Furthermore, the environmental strains of $A$. hydrophila and $A$. sobria produced more fluid than the clinical isolates $(\mathrm{p}<0.05)$. The strains of Aeromonas spp. that caused little or no fluid accumulation in the initial experiments became enterotoxin producers after 1-3 passages through RILs, regardless of their source, and showed gradual enhancement of fluid outpouring after each passage. The present study suggests that all strains of these species of Aeromonas are potentially enterotoxigenic, whether from clinical or environmental sources.
\end{abstract}

\section{Introduction}

Production of a heat-labile enterotoxin by clinical and environmental isolates of Aeromonas was first demonstrated in an adult rabbit ileal loop (RIL) model. ${ }^{1-3}$ Subsequently enterotoxin production by strains of Aeromonas was demonstrated in various other animal and tissue-culture assays. ${ }^{4-11}$ However, it was reported that, whereas clinical isolates of $A$. hydrophila and $A$. sobria produced enterotoxin, ${ }^{12-14}$ few or none of the environmental isolates did so. ${ }^{15,16}$ Other studies suggested that a smaller proportion of environmental strains of $A$. hydrophila and $A$. sobria, compared with those of diarrhoeal origin, are enterotoxigenic. ${ }^{17,18}$ Furthermore, strains of $A$. caviae from either clinical or environmental sources were reported to be rarely enterotoxin producers. ${ }^{9,10,19-21}$ Because these observations caused confusion about the enterotoxigenicity of Aeromonas spp., the present study was undertaken, with a large number of diarrhoeal and environmental isolates, to examine the enterotoxic activity of different species, and to correlate this with the sources of the isolates.

\section{Materials and methods}

\section{Strains of Aeromonas spp.}

We examined 147 strains (table), 54 isolated from cases of acute diarrhoea and 93 from environmental sources (water and fish). By the criteria of Popoff, ${ }^{22}$

Received 18 April 1991; accepted 27 June 1991

* Correspondence should be sent to Professor S. C. Sanyal. the strains were identified and classified into three species (A. hydrophila, A. sobria, A. caviae), according to their ability to hydrolyse aesculin, to ferment salicin, and to produce gas, acetoin and $\mathrm{H}_{2} \mathrm{~S}$. The organisms were maintained in peptone agar stab cultures at room temperature and did not undergo more than three subcultures before the experiments for enterotoxin production.

\section{Preparation of culture filtrates}

Culture filtrates of the strains were prepared by the method of Annapurna and Sanyal. ${ }^{3}$ Briefly, $10 \mathrm{ml}$ of Brain Heart Infusion Broth (BHIB; Difco) in a 50-ml conical flask was inoculated with 5-6 smooth separate colonies from overnight growth on nutrient agar (NA). The flasks were incubated at $37^{\circ} \mathrm{C}$ for $16-18 \mathrm{~h}$ in a shaking water bath with $80-120$ oscillations $/ \mathrm{min}$. The cultures were centrifuged at $22000 \mathrm{~g}$ for $20 \mathrm{~min}$ at $4^{\circ} \mathrm{C}$, and the supernates were filtered through $0 \cdot 22-\mu \mathrm{m}$ membrane filters (Millipore) and stored at $4^{\circ} \mathrm{C}$. Culture filtrate was prepared from a strain only when live cells caused fluid accumulation in RILs either before or after passage (see below).

\section{Enterotoxicity test}

Live bacteria and culture filtrates were tested for enterotoxicity in the adult RIL model by the method of De and Chatterje ${ }^{23}$ as adopted by Annapurna and Sanyal. ${ }^{2}$ Bacteria grown in BHIB for $3 \mathrm{~h}$ were diluted 10 -fold in the same medium and inoculated into RILs in doses of $1 \mathrm{ml}$ containing $10^{5}-10^{6} \mathrm{cfu}$. A BHIBculture of the toxigenic strain 569B of Vibrio cholerae 
was used as a positive control and unseeded BHIB as a negative control. Culture filtrates $(1 \mathrm{ml})$ were tested in the same way. Each test was done in three rabbits.

\section{Passage in RILs}

Successive passages of strains that caused little or no accumulation of fluid in the initial test were made in RILs as described by Sanyal et al ${ }^{24,25}$ Briefly, each strain was cultured aseptically from an RIL on NA and incubated overnight; five or six colonies were inoculated into BHIB and incubated for $3 \mathrm{~h}$, and $1 \mathrm{ml}$ of diluted culture was inoculated again into an RIL. The process continued until a good response was obtained.

\section{Results}

In the initial tests on the three species of Aeromonas in RILs, live cells of the majority (56\%) of the clinical and environmental isolates caused accumulation of fluid (table). Culture filtrates of these strains caused similar secretory response. With organisms from both sources, there were strain variations in the volume of fluid accumulation, and also variations between individual loops inoculated with the same strain (table).

Accumulation of fluid was caused by the majority of the strains of A. caviae- $55 \%$ of clinical and $65 \%$ of environmental isolates; live cells and culture filtrates caused similar fluid accumulation. However, live cells of $A$. hydrophila and $A$. sobria of environmental origin caused significantly more fluid accumulation $(\mathrm{p}<0.05)$ than those of $A$. caviae from either source (fig. 1); similar results were obtained with culture filtrates.
Furthermore, live cells and culture filtrates of $A$. hydrophila and $A$. sobria from environmental sources caused significantly more fluid accumulation $(\mathrm{p}<0.05)$ than the clinical isolates (fig. 1); but with $A$. caviae no significant difference $(\mathrm{p}>0.05)$ was found between strains of clinical and environmental origin.

The non-toxigenic strains of Aeromonas ( $44 \%$ of the isolates) belonging to all three species became enterotoxin producers after 1-2 passages through RILs, regardless of their origin (table), though three environmental isolates (one of each species) required three passages before they caused marked fluid accumulation. The initially non-toxigenic strains showed gradual enhancement of fluid outpouring after each passage: the findings with six representative strains (two of each species) are shown in fig. 2.

\section{Discussion}

The data of the present study indicate that not only the diarrhoeal isolates of $A$. hydrophila and $A$. sobria but almost equal proportions of environmental strains produce enterotoxin as judged by fluid accumulation in RILs, the classical model for detection of enterotoxic activity of bacteria. Moreover, most strains of $A$. caviae caused accumulation of fluid, whether they were of clinical or environmental origin (table). These data indicate that $A$. caviae produces enterotoxin and may cause diarrhoea in children, as suggested by its frequent isolation from the faeces of such cases in our study. Altwegg and Geiss ${ }^{18}$ and Namdari and Bottone ${ }^{26}$ also observed a very high association of this species with diarrhoea in children.

However, our observation that $A$. hydrophila and $A$. sobria caused significantly more accumulation of fluid

Table. Accumulation of fluid in RILs inoculated with BHIB cultures of three species of Aeromonas from clinical or environmental sources

\begin{tabular}{|c|c|c|c|c|c|}
\hline \multirow[b]{2}{*}{$\begin{array}{l}\text { Species } \\
\text { and } \\
\text { source }\end{array}$} & \multirow[b]{2}{*}{$\begin{array}{l}\text { Number } \\
\text { of } \\
\text { strains } \\
\text { tested }\end{array}$} & \multicolumn{2}{|c|}{ Strains tested before passage in RILs } & \multicolumn{2}{|c|}{ Strains tested after passage in RILs } \\
\hline & & $\begin{array}{l}\text { Number }(\%) \\
\text { causing } \\
\text { accumulation } \\
\text { of fluid }\end{array}$ & $\begin{array}{l}\text { Range of } \\
\text { volumes } \\
\text { of fluid } \\
(\mathrm{ml} / \mathrm{cm} \\
\text { of } \mathrm{RIL})^{*}\end{array}$ & $\begin{array}{l}\text { Number }(\%) \\
\text { causing } \\
\text { accumulation } \\
\text { of fluid }\end{array}$ & $\begin{array}{l}\text { Range of } \\
\text { volumes } \\
\text { of fluid } \\
(\mathrm{ml} / \mathrm{cm} \\
\text { of RIL)* }\end{array}$ \\
\hline \multicolumn{6}{|l|}{ A. hydrophila } \\
\hline Clinical & 5 & $3(60)$ & $0.5-0.7$ & $2(40)$ & $0 \cdot 7-1 \cdot 2$ \\
\hline Environmental & 9 & $5(56)$ & $0 \cdot 6-1 \cdot 7$ & $4(44)$ & $0 \cdot 8-1 \cdot 6$ \\
\hline \multicolumn{6}{|l|}{ A. sobria } \\
\hline Clinical & 27 & $15(56)$ & $0 \cdot 4-1 \cdot 0$ & $12(44)$ & $0 \cdot 5-1 \cdot 0$ \\
\hline Environmental & 33 & $14(42)$ & $0 \cdot 5-1 \cdot 3$ & $19(58)$ & $0 \cdot 6-1 \cdot 5$ \\
\hline \multicolumn{6}{|l|}{ A. caviae } \\
\hline Clinical & 22 & $12(55)$ & $0.4-0.9$ & $10(45)$ & $0 \cdot 5-1 \cdot 2$ \\
\hline Environmental & 51 & $33(65)$ & $0.5-1 \cdot 0$ & $18(35)$ & $0 \cdot 5-1 \cdot 2$ \\
\hline Positive control† & & & $0.8-1.5$ & & \\
\hline Negative controlł & & & $0 \cdot 0-0 \cdot 0$ & & \\
\hline
\end{tabular}

* The stated range of volumes was observed in three RILs inoculated with each strain. + BHIB-culture of strain $569 \mathrm{~B}$ of $V$. cholerae. †BHIB. 


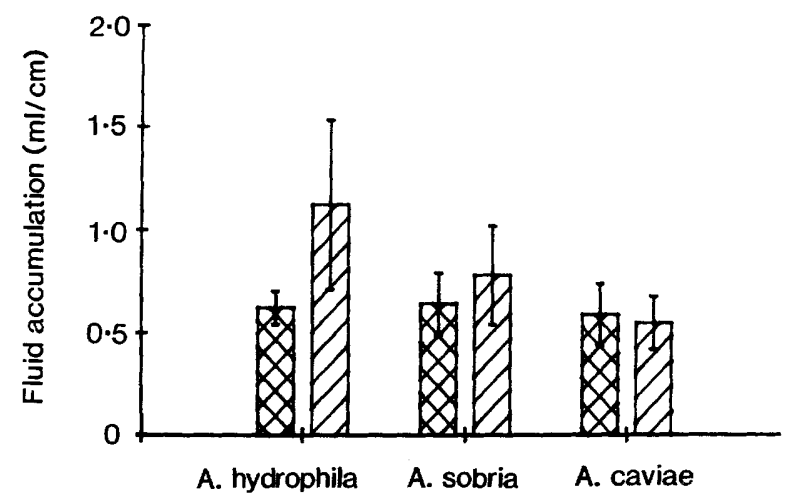

Fig. 1. Enterotoxicity of clinical $\$$ and environmental $\square$ isolates of three species of Aeromonas in initial experiments before RIL passage. The bars on the columns indicate the range of fluid accumulation caused by different strains.

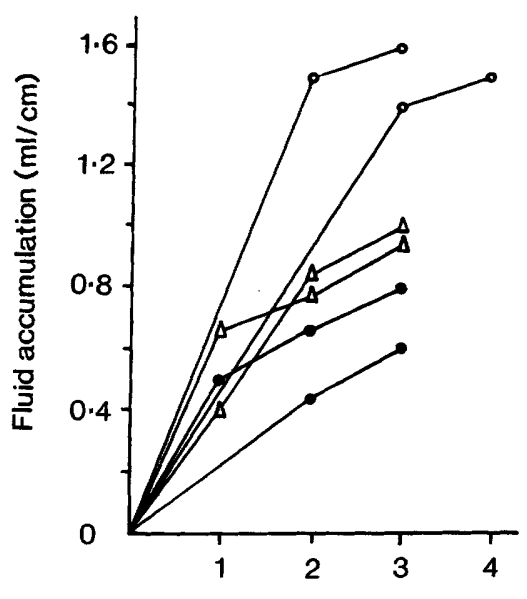

Number of passages in RILs

Fig. 2. Influence of RIL passage on volume of fluid accumulation caused by two representative strains of each species which were non-toxigenic when tested initially: $\boldsymbol{A}$. hydrophila $\mathrm{O}-\mathrm{O}, \boldsymbol{A}$. sobria - A. caviae $\triangle-\triangle$.

than $A$. caviae suggests higher enterotoxic activity, which may explain the less frequent detection of enterotoxic activity in strains of $\boldsymbol{A}$. caviae; but, in our study, a similar proportion of the strains of all three species produced enterotoxin (table), suggesting no species-specific difference in enterotoxigenic potential.

The environmental strains of $A$. hydrophila and $A$. sobria caused significantly more accumulation of fluid than the clinical isolates (fig. 1). A probable explanation of this difference in the degree of enterotoxicity may be the observation that, compared with clinical isolates, strains of environmental origin produced quantitatively more constitutive chitinase, and some strains even elaborated inducible chitinase; both these properties correlated with higher enterotoxicity (unpublished data).

The large number of clinical and environmental strains that caused little or no accumulation of fluid in the initial experiments showed enhancement of their enterotoxic activity after only 1-2 passages through the susceptible rabbit ileum. Similar observations on the effect of passage through the gut of a susceptible host were made earlier, ${ }^{3}$ and also with many other organisms such as $V$. cholerae non-O1, ${ }^{27}$ Plesiomonas shigelloides, ${ }^{28} \mathrm{~V}$. fluvialis, ${ }^{29} \mathrm{~V}$. mimicus, ${ }^{24,30} \mathrm{CT}$-genenegative $V$. cholerae $\mathrm{O}^{25}$ and Klebsiella pneumoniae. ${ }^{31}$ Further, it is known that the so-called hypertoxigenic strain 569B of $V$. cholerae $\mathrm{O} 1$ also requires passage through rabbit gut for enhancement of toxin production; a mechanism of repression of toxin gene which becomes expressed on passage in a susceptible host may account for this phenomenon. ${ }^{32}$ There is every likelihood that toxigenicity of our fresh isolates may have decreased during 1-3 subcultures in vitro before the loop tests. It appears that repression-derepression of a virulence factor in a bacterial strain is a means of its adaptation to a particular micro-environment.

Strains of the three species of Aeromonas produced quantitatively more toxin after each passage (fig. 2). This may suggest that Aeromonas, being ubiquitous in our aquatic environment, may have easy access to the human intestine in a community with suboptimal hygienic conditions, and therein develop increased enterotoxicity. The present study demonstrates that strains of all three species are potentially enterotoxigenic regardless of their source.

The study was supported by a fellowship to D.V.S. from the Council of Scientific and Industrial Research, New Delhi, and by the Indian Council of Medical Research grant No. 5/8-1/(49)/88 ECD II. The authors gratefully acknowledge the secretarial assistance of Mr D. Venu Gopal.

\section{References}

1. Sanyal SC, Singh SJ, Sen PC. Enteropathogenicity of Aeromonas hydrophila and Plesiomonas shigelloides. $J$ Med Microbiol 1975; 8: 195-199.

2. Annapurna E, Sanyal SC. Studies on enteropathogenicity of Aeromonas hydrophila in an experimental model. Indian $J$ Prev Soc Med 1975; 6: 234-237.

3. Annapurna E, Sanyal SC. Enterotoxigenicity of Aeromonas hydrophila. J Med Microbiol 1977; 10: 317-323.

4. Dubey RS, Sanyal SC. Enterotoxicity of Aeromonas hydrophila: skin responses and in vitro neutralisation. Zentralbl Bakteriol A 1978; A242: 487-499.

5. Ljungh A, Popoff M, Wadström T. Aeromonas hydrophila in acute diarrheal disease: detection of enterotoxin and biotyping of strains. J Clin Microbiol 1977; 6: 96-100.

6. Dubey RS, Sanyal SC, Malhotra OP. Purification of Aeromonas hydrophila enterotoxin and its mode of action in experimental model. In: Eaker D, Wadström T (eds) Natural toxins. Oxford, Pergamon Press. 1980: 259-268.

7. Burke V, Robinson J, Berry RJ, Gracey M. Detection of enterotoxins of Aeromonas hydrophila by a suckling-mouse test. J Med Microbiol 1981; 14: 401-408.

8. Chakraborty T, Montenegro MA, Sanyal SC, Helmuth R, Bulling $\mathrm{E}$, Timmis $\mathrm{KN}$. Cloning of enterotoxigenic gene from Aeromonas hydrophila provides conclusive evidence of production of a cytotoxic enterotoxin. Infect Immun $1984 ; 46: 435-441$.

9. Turnbull PCB, Lee JV, Miliotis MD et al. Enterotoxin production in relation to taxonomic grouping and source of isolation of Aeromonas species. J Clin Microbiol 1984; 19: 175-180. 
10. Barer MR, Millership SE, Tabaqchali S. Relationship of toxin production to species in the genus Aeromonas. $J$ Med Microbiol 1986; 22: 303-309.

11. Kuijper EJ, Steigerwalt AG, Schoenmakers BS, Peeters MF, Zanen HC, Brenner DJ. Phenotypic characterization and DNA relatedness in human fecal isolates of Aeromonas spp. J Clin Microbiol 1989; 27 : 132-138.

12. Daily OP, Joseph SW, Coolbaugh JC et al. Association of Aeromonas sobria with human infection. $J$ Clin Microbiol $1981 ; 13: 769-777$.

13. Millership SE, Barer MR, Tabaqchali $S$. Toxin production by Aeromonas spp. from different sources. J Med Microbiol 1986; $22: 311-314$

14. Eko FO, Utsalo SJ. Characterization and significance of Aeromonas spp. isolated from diarrhoeic stools in Nigeria. J Trop Med Hyg 1989; 92: 97-101.

15. Seidler RJ, Allen DA, Lockman H, Colwell RR, Joseph SW, Daily OP. Isolation, enumeration, and characterization of Aeromonas from polluted waters encountered in diving operations. Appl Environ Microbiol 1980; 39: 1010-1018.

16. Lechevallier MW, Evans TM, Seidler RJ et al. Aeromonas sobria in chlorinated drinking water supplies. Microbiol Ecol $1982 ; 8: 325-333$.

17. Burke V, Robinson J, Gracey M, Peterson D, Meyer N, Haley V. Isolation of Aeromonas spp. from an unchlorinated domestic water supply. Appl Environ Microbiol 1984; 48 : 367-370.

18. Altwegg M, Geiss HK. Aeromonas as human pathogen. $C R C$ Crit Rev Microbiol 1989; 16: 253-286.

19. Burke V, Robinson J, Atkinson HM, Gracey M. Biochemical characters of enterotoxigenic Aeromonas spp. $J$ Clin Microbiol 1982; 15 : 48-52.

20. Janda JM. Biochemical and exoenzymatic properties of Aeromonas species. Diagn Microbiol Infect Dis 1985; 3: 223-232.

21. Majeed KN, Egan AF, MacRae IC. Incidence of aeromonads in samples from an abattoir processing lambs. $J$ Appl Bacteriol $1989 ; 67$ : 597-604.

22. Popoff M. Genus III. Aeromonas. Kluyver and Van Niel. 1936 In : Krieg NR, Holt JG (eds) Bergey's Manual of systematic bacteriology, 9th edn. Baltimore, Williams and Wilkins Co. $1984 ; 1$ : $545-548$.

23. De SN, Chatterje DN. An experimental study of the mechanism of action of Vibrio cholerae on the intestinal mucous membrane. J Pathol Bacteriol 1953; 66: 559-562.

24. Sanyal SC, Huq MI, Neogy PKB, Alam K, Kabir MI, Rahaman ASMH. Experimental studies on the pathogenicity of Vibrio mimicus strains isolated in Bangladesh. Aust $J$ Exp Biol Med Sci 1984; 62: 515-521.

25. Sanyal SC, Neogi PKB, Alam K, Huq MI, Al-Mahmud KA. A new enterotoxin produced by Vibrio cholerae $01 . J$ Diarrhoeal Dis Res 1984; 2 : 3-12.

26. Namdari H. Bottone EJ. Microbiologic and clinical evidence supporting the role of Aeromonas caviae as a pediatric enteric pathogen. J Clin Microbiol 1990; 28 : 837-840.

27. Shankar P, Agarwal RK, Sanyal SC. Experimental studies on enteropathogenicity of Vibrio cholerae serotypes other than 1. Zentralbl Bakteriol Hyg A 1982; 252: 514-524.

28. Sanyal SC, Saraswathi B, Sharma P. Enteropathogenicity of Plesiomonas shigelloides. J Med Microbiol 1980; 13: 401409.

29. Sanyal SC, Agarwal RK, Annapurna E, Lee JV. Enterotoxicity of group F vibrios. Jpn J Med Sci Biol 1980; 33: 217-222.

30. Sanyal SC, Huq MI, Neogy PKB, Alam K, Rahman ASMH. Vibrio mimicus as an aetiologic agent of diarrhoea and its pathogenesis. Indian J Med Microbiol 1983; 1: 1-12.

31. Raychaudhury A, Agarwal RK, Sanyal SC. Enteropathogenicity of Klebsiella pneumoniae strains isolated from stools of diarrhoeal patients and other clinical specimens: an experimental study. Zentralbl Bakteriol Hyg A 1984; 258 : 94-103.

32. Singh SJ, Sanyal SC. Enterotoxicity of the so-called NAG vibrios. Ann Soc Belg Med Trop 1978; 58: 133-140. 